Aletria, Belo Horizonte, v. 30, n. 1, p. 65-81, 2020

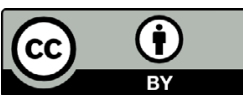

\title{
Silviano, autor de Derrida
}

\section{Silviano, Author of Derrida}

\author{
Eneida Maria de Souza \\ Universidade Federal de Minas Gerais (UFMG), Belo Horizonte, Minas Gerais / Brasil \\ eneidamariasouza@gmail.com \\ http://orcid.org/0000-0002-5018-4931
}

Resumo: Este ensaio pretende discorrer sobre o trajeto teórico da obra de Silviano Santiago, iniciada no artigo seminal "O entre-lugar do discurso latino-americano", de 1971, presente no livro Uma literatura nos trópicos. Sem me deter no legado literário do escritor diante da cultura literária estrangeira, faço considerações sobre o diálogo mantido entre conceitos desenvolvidos pelo teórico nacional e os estrangeiros, a partir de um processo de montagem reflexiva sobre o entre-lugar. O procedimento visa não só a atualidade de uma leitura do conceito do ponto de vista anacrônico, não evolutivo, mas tenta apontar coincidências verificadas pelo autor entre outros pensadores, à medida que estas foram surgindo ao longo do tempo.

Palavras-chave: entre-lugar; montagem; anacronia; autoria; Borges; Piglia.

Abstract: This paper aims at discussing the theoretical path of Silviano Santiago's work, which began in the seminal article "Latin-American discourse: the space in-between", from 1971, part of the book A Literature in the Tropics. Leaving aside the writer's legacy concerning foreign literary culture, I shall consider the dialogue established between concepts developed by the national theoretician and by foreigners, in a process of reflexive exploration on the space in-between. This procedure consists not only in reading the concept from the anachronistic, non-evolutionary point of view, but also in pointing out the coincidences noted by the author among other thinkers as these commonalities appeared over time.

Keywords: the space in-between; montage; anachrony; authorship; Borges; Piglia. 


\begin{abstract}
A tradição literária tem a estrutura de um sonho no qual se recebem as lembranças de um poeta morto. Podemos imaginar alguém que no futuro (num quarto de hotel, em Londres) comece de repente a ser visitado pelas lembranças de um obscuro escritor sul-americano a quem apenas conhece. [...]

Talvez no futuro alguém, uma mulher que ainda não nasceu, sonhe que recebe a memória de Borges tal como Borges sonhou que recebia a memória de Shakespeare.
\end{abstract}

PIGLIA, 1999, p. 19-20.

"A memória de Shakespeare", conto de Borges que narra como a memória do autor inglês foi presenteada ao narrador/escritor por um desconhecido, não estaria sendo reconfigurada, na literatura contemporânea, pela memória de Borges? A metáfora da memória alheia permitiria definir a tradição poética e a herança cultural da literatura contemporânea? Estaria a profecia de Ricardo Piglia, segundo a qual a memória de um escritor latino-americano poderia ser enxertada, no futuro, na memória de um europeu? E, acrescentaria, na memória de tantos outros escritores do planeta? O legado literário do cânone ocidental, no qual o Norte sempre se impôs como exportador de modelos, estaria sendo ocupado pelo Sul ou pela literatura dita periférica? Ou ainda, a escolha dos precursores literários, realizada contra a passividade da influência, não poderia ser lida como prisão, mais do que como presente, recebido, por sua vez, como herança nefasta?

Estas considerações iniciais foram motivo de um texto por mim escrito sobre Borges, intitulado "A memória de Borges" (ver SOUZA, 2010), por meio do qual pretendo articular a relação com o trajeto teórico da obra de Silviano Santiago, iniciada no artigo seminal "O entre-lugar do discurso latino-americano", de 1971, presente no livro Uma literatura nos trópicos. ${ }^{1}$ Sem me deter no legado literário do escritor diante da cultura literária estrangeira, faço considerações sobre o diálogo mantido entre conceitos desenvolvidos pelo teórico nacional e os estrangeiros, a partir de um processo de montagem reflexiva sobre o entre-lugar. $O$ procedimento visa não só a atualidade de uma leitura do conceito do ponto de vista anacrônico, não evolutivo, mas na tentativa de apontar coincidências verificadas pelo autor entre outros pensadores,

\footnotetext{
${ }^{1}$ Este artigo é um desdobramento de outros dois trabalhos, intitulados, primeiramente "A memória de Borges" (ver SOUZA, 2010), em segundo lugar "Ficções impuras" (ver SOUZA, 2014).
} 
à medida que estas foram surgindo ao longo do tempo. A percepção de ser a propriedade autoral categoria há muito discutida, entende-se aqui até que ponto as associações entre conceitos independem do momento em que foram criados, embora sejam datados, e de quem recebeu a assinatura. $\mathrm{O}$ estatuto autoral não se inscreve pelo sentimento de posse, mas como invenção e diferença, pelo diálogo desconstrutor com o outro. Não é gratuita a menção no parágrafo final do artigo à antropofagia e ao endosso da proposta modernista oswaldiana como traço significativo para a diluição da autoria pelo instinto predatório do roubo: "Só me interessa o que não é meu” (ANDRADE, 1970, p. 13). O instinto antropológico do crítico o levou a privilegiar princípios norteadores da operação de natureza cultural quanto à questão da dependência. $\mathrm{O}$ que importa, portanto, é a liberdade conferida à montagem construída pelo leitor, o qual se despe do mesmo sentimento de propriedade, sem nomear quem primeiro elaborou a reflexão. Refiro-me à importância e ao rendimento que o conceito de entre-lugar exerce no meio acadêmico e alhures, ao se deslocar de seu autor nacional e se alçar a uma rede global de teóricos, os quais passam a ser lidos principalmente pelo leitor mais contemporâneo, pelo viés do olhar de Silviano Santiago.

O entre-lugar se expande e se multiplica com a apropriação de diversos pensadores, os quais respondem não só pela literatura, mas abrangem os discursos filosófico, social, antropológico e político. Sobrevive sem a marca da cópia e da repetição pura, mas se insere no âmbito da impureza e da traição. Em artigo esclarecedor, Denilson Lopes afirma ser a leitura de Silviano um convite a "não ler com (por dentro ou em companhia) nem ler contra, ler entre, o que possibilita movimentos, deslocamentos, infidelidades, aproximações e afastamentos" (LOPES, 2012, p. 8).

Sem a pretensão de valorizar o lugar do teórico diante do quadro composto por representantes do pensamento estrangeiro entre nós, ressalto aqui a memória de Borges como incentivadora de um dos empréstimos do crítico para a apropriação/construção do conceito como ruptura das noções de fonte e influência. Reitera a conhecida premissa do escritor argentino de ser o autor aquele que desconsidera origens, por ser ele quem elege seus precursores. Nesse sentido, consegue-se entender claramente um dos motivos de se pensar o entre-lugar como diluidor de fronteiras rígidas entre temporalidades e espaçamentos culturais e refletir sobre o deslocamento como regra básica desse movimento. $\mathrm{O}$ 
deslocamento implica a saída de lugares fixos, da voz autoral e do culto da personalidade, com a intenção de romper a relação mimética com o outro e considerá-lo na condição de diferença, pelo gesto incompleto do suplemento.

Esse outro metaforiza-se ainda em várias imagens, no sentido de estar o autor/leitor esvaziado do signo de propriedade, aberto ao diálogo, à fala e à linguagem, esta também carente de autoridade. Entre vozes restauradoras e sobreviventes, escritores se encontram e passam a conviver imaginariamente com seus precursores, em que são rompidas as cadeias sucessivas de causa/efeito, anterioridade/posterioridade, próprias do pensamento hegemônico da influência. A ideia de precursor, no entender de Borges, define-se pelo afastamento do passado como mestre e pai de discursos futuros, ao se inscrever como espectro de novos autores: "O fato é que cada escritor cria seus precursores. Seu trabalho modifica nossa concepção do passado, como há de modificar o futuro. Nessa correlação, não importa identidade ou a pluralidade dos homens" (BORGES, 1999, p. 98).

Liberta-se o autor da passividade inerente à ideia de herança $\mathrm{e}$ filiação, tornando-se contemporâneo de quem escolhe como parceiro. $O$ procedimento anacrônico dos encontros entre escritores pertencentes a épocas distintas propõe a desobediência aos parâmetros temporais, pela concepção simultânea entre presente, passado e futuro. "Pierre Menard, autor do Quixote", instaura na pauta literária e na crítica comparada a leitura periférica como resistência à submissão do tempo, caracterizado na sua sucessividade e teleologia. Endossa o anacronismo como técnica nova, por recusar a concepção de história literária segundo moldes hierárquicos e excludentes. A autoria sofrerá, igualmente, outros contornos, pelo deslocamento de sua natureza absoluta:

Menard (talvez sem querê-lo) enriqueceu, mediante uma técnica nova, a arte fixa e rudimentar da leitura: a técnica do anacronismo deliberado e das atribuições errôneas. Essa técnica de aplicação infinita nos leva a percorrer a Odisseia como se fosse posterior à Eneida e o livro Le Jardin du Centaure de Madame Henri Bachelier como se fosse de Madame Henri Bachelier. Essa técnica povoa de aventura os livros mais pacíficos. Atribuir a Louis Ferdinand Céline ou a James Joyce a Imitação de Cristo não é suficiente renovação dessas tênues advertências espirituais? (BORGES, 1999, p. 498). 
$\mathrm{Na}$ atualização da "técnica do anacronismo", desconstrói-se a paternidade e a filiação das obras, posição que será mais tarde endossada pela filosofia de Jacques Derrida, estampada, principalmente, no texto A farmácia de Platão (1972). A escrita, ao contrário do logos, do discurso oral, afasta-se do pai e inscreve-se como alteridade e ausência de autoridade. Na condição de simulacro da fala, a escrita é ainda interpretada como parricida, desfazendo-se a ligação com a origem. No ensaio "Kafka e seus precursores", Borges insinua que a prática de romper com a sequência temporal necessariamente aponta para a fragilidade autoral. $\mathrm{O}$ engendramento dos precursores implica a aceitação, da parte de quem assim se comporta, da parceria como razão de ser da criação. $\mathrm{O}$ escritor argentino defendia, com base nessa equação, o anonimato, a transformação da obra em bem comum, desvinculando-se da presença autoritária do criador e despindo-se das insígnias de propriedade.

A extrema visibilidade que a autoria poderia adquirir, ao longo do tempo, pulveriza-se no gesto contrário, o da invisibilidade do autor como sujeito pleno no ato criador. Nessa operação, Borges se impõe como imagem do escritor clássico, anônimo, despersonalizado, embora o ato responsável pelo desaparecimento seja, ironicamente, o momento de maior fulguração póstuma. Um dos maiores desejos do escritor concentrase na transformação da humanidade em ideal de construção coletiva dos saberes, em que cada indivíduo seja capaz de se considerar artista e criador. $\mathrm{O}$ anonimato significaria a recusa de hierarquias e de propriedade autoral, uma vez que se postula o gesto democrático de recepção e produção do conhecimento. As afirmações do escritor argentino quanto ao anonimato revestem-se, contudo, de certa pose de intelectual, ao se abdicar da fama conquistada, e de permitir ter sua imagem diluída entre tantas outras. Não é de se estranhar, portanto, que um escritor, ao atingir o anonimato, estaria penetrando no reconhecimento popular e se integrando, de forma plena, no cânone universal. Nas suas palavras,

Espero chegar a uma idade sem aniversários, sem coleções, sem museus. Tenho um conto que se intitula "Utopia do homem que está cansado", no qual se supõe que todo homem se dedica à música, que todo homem é seu próprio Brahms; que todo homem se dedica à literatura, que todo homem é seu próprio Shakespeare. E mais tarde, quando morre, destrói-se toda sua obra, porque todo homem é capaz de produzi-la. E desde então, não há clássicos, e 
não há memória, e não há bibliotecas. Porque todo homem pode produzir uma galeria, ou pode erguer e construir uma casa. [...] Que não tivesse... que nenhum indivíduo tivesse nome. Que todo livro que se publicasse fosse anônimo. (BORGES, 1988, p. 270, tradução de Graciela Ravetti). ${ }^{2}$

Ao adotar esse espaço intermediário de reflexão, atingido ainda pela mediação de Borges e de Derrida, o crítico brasileiro descarta "o lugar-comum dos nacionalismos brabos" e o "lugar-fetiche do aristocrata saber europeu", como assinala ao definir o termo. Elege os precursores com a intenção de reforçar o lugar teórico entre e o insere na dimensão cultural como futura estratégia no combate à dependência. A presença de Borges, ao lado de Derrida, inscreve o pensamento do teórico na congruência de precursores os quais se caracterizam por um pensamento comum quanto à diluição de paradigmas temporais e asserções de ordem filosófica. Não é gratuita a escolha de autores cujo perfil intelectual oscila entre ensaio e ficção, filosofia e literatura. Escritores que se situam entre lugares flutuantes do saber, espaços ambivalentes responsáveis pela quebra do raciocínio binário, ao optarem pela convivência paradoxal entre os termos a serem negociados. A crítica ao racionalismo já estaria implícita na preferência de Silviano pelo escritor latino-americano e o filósofo franco-argelino. Postulações ligadas à interpretação do tempo no seu aspecto anacrônico ou à diluição da ideia de origem como princípio norteador das diferenças culturais embasam a produção do conceito de entre-lugar. A definição do conceito encontra-se claramente assumida pelo "entre-autor" nos seguintes termos:

Borges me deu a coragem do pensamento paradoxal quando estava preparado (ou estavam me preparando) para os caminhos da racionalidade francesa numa terra

\footnotetext{
2 "Yo espero llegar a una edad sin aniversarios, sin colecciones, sin museos. Tengo un conto que se titula 'Utopia de un hombre que está cansado', en el que se supone que todo hombre se dedica a la música, que todo hombre es su proprio Brahms; que todo hombre se dedica a la literatura, que todo hombre es su proprio Shakespeare. Y luego, cuando muere, se destruye toda su obra, porque todo hombre es capaz de producirla. Y no hay clásicos, y no hay memoria, y no hay bibliotecas, desde luego. Porque todo hombre puede producir una biblioteca, o puede producir una galería, o puede elevar una estatua o construir una casa. [...] Que no hubiera... que ningún individuo tuviera nombre. Que todo libro que se publicara fuera anónimo."
} 
onde os lugares-comuns nos impelem para o irracional. Nunca fui vítima da lucidez racional da Europa como um novo Joaquim Nabuco, nem me deixei seduzir pelo espocar dos fogos de artifício ou pelas cores do carnaval nos trópicos. Fiquei com os dois e com a condição de viver e pensar os dois. Paradoxalmente. Nem o lugarcomum dos nacionalismos brabos, nem o lugar-fetiche do aristocrata saber europeu. Lugar-comum e lugar-fetiche imaginei o entre-lugar e a solidariedade latino-americana. Inventei o entre-lugar do discurso latino-americano que já tinha sido inaugurado pelos nossos melhores escritores. (SANTIAGO, 2001, p. 434).

Entre a sedução das cores do carnaval dos trópicos e do racionalismo europeu, o crítico elege o raciocínio paradoxal como antídoto para a orientação totalizadora e a universalização, na defesa de um pensamento transcultural, que se desvincula do ponto de vista estritamente nacional e da prisão a modelos estrangeiros. Nesse sentido, amplia e reconhece o poder de força dos textos ditos colonizados, a favor da leitura que se processa pela via periférica, sem o aparato determinista, pautado pelo regime de oposições. Como núcleo operador da diferença, as relações entre os polos comparativos são marcadas pelo endosso de categorias que matizam o binarismo e contemplam as noções de paradoxo, indecidibilidade, heterogeneidade, hibridez, mestiçagem, entre outras.

A polêmica suscitada pelo artigo merece ser retomada, com vistas a sinalizar as distintas posições assumidas por outros teóricos brasileiros. No entender de Roberto Schwarz, em "Nacional por subtração", de 1987, artigo dedicado à discussão das teorias da dependência realizadas por Silviano Santiago e Haroldo de Campos, respectivamente em Uma literatura nos trópicos e "Da razão antropofágica: diálogo e diferença na cultura brasileira": "a filosofia francesa recente é outro fator no descrédito do nacionalismo cultural, [...] e, de certo ângulo, em lugar da almejada europeização ou americanização da América Latina, assistiríamos à latino-americanização das culturas centrais" (SCHWARZ, 1987, p. 35-36). A reflexão vai de encontro às posições de Borges, Piglia, Silviano e Haroldo, autores que romperam com o preconceito de sermos representantes do descompasso com a cultura europeia, pelo fato de estarmos sempre distorcendo o que havia sido originalmente concebido. Explica-se, dessa forma, a formulação do crítico quanto ao conceito das "ideias fora-do-lugar". 
Considerar, portanto, a "latino-americanização das culturas centrais" como saída absurda e invertida para o desafio da dependência contraria a proposta defendida por esses pensadores em reconhecer que as culturas periféricas se inserem nas metropolitanas. "Eça, autor de Madame Bovary", outro artigo presente em Uma literatura nos trópicos, expõe com nitidez o legado borgiano da leitura da tradição literária como resposta às questões de simultaneidade e coexistência de tempos e espaços. Rompendo-se com a continuidade temporal e a hierarquia valorativa de quem veio primeiro, propõe-se o espaço do meio como abertura para o movimento e o deslocamento, procedimentos responsáveis pela consolidação da ruptura com a ordem vertical e hierárquica dos empréstimos. Nesse sentido, Schwarz confirma, pela negação, o sentimento desejado por Piglia, ao imaginar no futuro alguém recebendo, em sonho, a memória de Borges, ou por Silviano, ao conceber Eça como autor de Madame Bovary.

Curiosamente, a filosofia francesa de décadas anteriores, culpada pelo descaso de teóricos brasileiros com os nacionalismos tropicais, permanece atual, motivando o acréscimo de associações a serem feitas com a diluição do tempo contínuo para a compreensão das reviravoltas pós-coloniais. O texto de Deleuze e Guattari, "Rizoma", de 1976, incluído em Mil platôs em 1980, é posterior à publicação do artigo seminal de Silviano. No entanto, tornam-se contemporâneos, à medida que os lugares dos saberes localizam-se na superfície plana e múltipla dos empréstimos. $\mathrm{Na}$ concepção comum de um tempo paradoxal que afeta todos os acontecimentos, não se cogita a aceitação da linearidade das descobertas, mas na simultaneidade operada em relação às mesmas. $\mathrm{O}$ conceito de rizoma, desenvolvido pelos autores, é análogo à desconfiança quanto às raízes, às arvores genealógicas e à obediência às origens, posições assumidas pela crítica literária da época e, atualmente, endossadas por grande parcela de teóricos contemporâneos. Situando-se em oposição às noções de hierarquia e verticalidade imputadas às influências, o entre-lugar ressurge estampado nos textos de Deleuze e Guattari como signo da aliança, do caminho do meio, do intermezzo. Nada impulsiona a preocupação com o que veio antes ou o que veio depois. Nas palavras dos filósofos, outra lógica de descortina a favor da dissolução dos fundamentos: "Mas ainda, é a literatura americana, e já inglesas, que manifestaram este sentido rizomático, souberam mover-se entre as coisas, instaurar uma lógica do E, reverter a ontologia, destruir o fundamento, 
anular fim e começo" (DELEUZE; GUATTARI, 2004, p. 37). Silviano, autor de Deleuze e Guattari?

Ricardo Piglia, escritor latino-americano, em perfeita simetria com Borges e Silviano, elaborou a sexta proposta de Italo Calvino, autor italiano das Seis propostas para o próximo milênio, no desejo de responder ao impulso criativo de completar a falta deixada pelo discurso europeu. Ao propor o desafio, incita o diálogo e se coloca como leitor/ autor de um texto presumidamente intocável e completo. Seria pertinente considerar essa resposta como liberdade em relação ao precursor, por considerar, como Calvino, autor das propostas, e se inscrever no texto considerado como acabado e pertencente ao seu criador. No entanto, o texto adquire vida, ou melhor, sobrevida, pela inserção de uma voz vinda dos trópicos, integrando-se, de forma anacrônica e enriquecedora, à voz europeia. Denominada por Piglia de "deslocamento e distância", a sexta proposta atua como alerta de uma literatura a ser pensada num tempo futuro, escrita a partir das margens, ao sinalizar uma perspectiva distinta da versão original, sem destruí-la. Cito:

Pensei que talvez alguém poderia escrever essa proposta que falta. Qual seria a sexta proposta não escrita para o próximo milênio? Qual seria a proposta escrita a partir de Buenos Aires, escrita nesse subúrbio do mundo? Como veríamos o futuro da literatura ou a literatura do futuro e sua função? Não como alguém de um país central com sua grande tradição cultural. Levantamos, assim, esse problema a partir da margem, da periferia das tradições centrais, olhando de forma oblíqua. [...] A tentativa de imaginar que valor poderia subsistir é, evidentemente, uma ficção especulativa, uma espécie de versão utópica de Pierre Menard, autor do Quixote. Não exatamente como seria reescrita literalmente uma obra-prima do passado, mas como seria reescrita imaginariamente a obra-prima do futuro. (PIGLIA, 2001, p. 2, tradução de Rômulo Monte Alto). ${ }^{3}$

\footnotetext{
3 "Pensé que quizá se podría escribir esa propuesta que falta. Cuál sería la sexta propuesta no escrita para el próximo milenio? Y cuál sería esa propuesta escrita desde Buenos Aires, escrita desde este suburbio del mundo? Como veríamos nosotros el futuro da literatura o la literatura del futuro y su función? No como lo ve alguien en un país central con una grande tradición cultural. Nos planteamos entonces ese problema desde el margen, desde el borde de las tradiciones centrales, mirando el sesgo. [...] El intento de
} 
Assim como Piglia, Silviano torna-se também autor do entrelugar derridiano, do entre-lugar da literatura latino-americana, enquanto tradutor do deslocamento que se efetua pelas margens e pela reescrita do conceito elaborado pelo filosófico francês. Em virtude da leitura enviesada dos textos críticos e da literatura do escritor, cria-se a abertura para o entendimento do panorama teórico transcultural, o aceno para o futuro, como assim se expressa o escritor argentino. Essa proposta retoma também a fórmula borgiana de Pierre Menard, relendo-a sob o signo do deslocamento, ao pensar a reescrita imaginária de uma obra-prima futura na sua condição de uma literatura potencial. Estar fora do centro teria, assim, suas vantagens, pela atitude audaciosa de assumir a alteridade como resistência e dialogar com o devir como resposta à herança legada pelas culturas hegemônicas. A reescrita das tradições centrais não se configura nos moldes da repetição e da cópia, mas no artifício imaginativo de criação de uma "ficção especulativa". O devir-literatura dos trópicos deveria contar com o possível desenho de manifestações literárias que mantivessem o traço definidor da arte periférica. Não resta dúvida de que os estudos de literatura comparada e de crítica cultural dos últimos quarenta anos são devedores da contribuição inestimável de um grupo de intérpretes interessados em reverter posições colonialistas e em repensar os impasses e equívocos da situação pós-colonialista em termos políticos e como resultado da desconstrução derridiana.

Na revisão do conceito, ensaiado ao longo desta reflexão, introduzi um terceiro termo na equação, na figura de Ricardo Piglia, com o intuito de tornar o raciocínio não só pautado pela presença de outro escritor latino-americano, mas como mediação para destituir o sentimento de propriedade do conceito a ser atribuído a um autor específico. Contemporâneo de Silviano, sua obra ficcional e crítica mantém pontos de contato com a do escritor brasileiro, na fabulação conjunta de textos que discorrem sobre dependência cultural e na posição desconstrutora a respeito da produção artística, sempre pensada em termos de diálogo e inserção no concerto cultural das nações. A esperança de alguém, no futuro, receber a memória de Borges, como este recebeu a memória de Shakespeare, seria um desejo alimentado também por Silviano ao propor

imaginar qué valor podría persistir es, por supuesto, una ficción especulativa, una suerte de versión utópica de Pierre Menard, autor del Quijote. No tanto como reescribiríamos literalmente una obra maestra del pasado sino como reescribiríamos imaginariamente la obra maestra del futuro." 
a mudança de paradigma (discursos de formação) para o entendimento da situação da literatura brasileira como inserida na literatura universal (discursos da inserção). Por meio dos discursos de inserção, tenta-se reconduzir o conceito de entre-lugar na dimensão futura e talvez invertida, em que não se problematiza mais o lá e o cá, uma vez que os lugares tornam-se intercambiáveis e paradoxais. Em texto recente, Silviano esclarece este ponto de vista:

Faz-se urgente dar uma posição à "inserção da linguagemBrasil em contexto universal", para retomar palavras premonitórias de Hélio Oiticica no texto "Brasil diarreia" (Arte brasileira hoje, 1973). Inserir a linguagem-Brasil em contexto universal traduz a vontade de situar um problema que se alienaria fosse ele local, pois problemas locais não significam nada - se se fragmentam quando expostos a uma problemática universal. Tornam-se irrelevantes se situados somente em relação a interesses locais. E Hélio conclui: “A urgência dessa 'colocação de valores' num contexto universal é o que deve preocupar realmente àqueles que procuram uma 'saída' para o problema brasileiro.” (SANTIAGO, 2015, p. 22).

\section{Ficções teóricas}

Warburg inventa uma "iconografia dos intervalos", para retomar expressão de Freud em carta a Fliess (16/4/1896), "nosso reino é o entre-lugar". [...] A teoria é o entre-lugar ficcional que reposiciona as imagens do Novo Mundo no Ocidente e as deste nas Américas. Os trópicos não são tristes. Tornaram-se tristes.

Silviano Santiago

Em artigos publicados inicialmente no Estado de S. Paulo e reeditado no livro de ensaios Aos sábados, pela manhã, "Ficção teórica" e "Renascença: movimento e gestual", Silviano considera-se contemporâneo do historiador de arte alemão Aby Warburg. ${ }^{4}$ Justifica

\footnotetext{
${ }^{4}$ Algumas considerações presentes na passagem que se segue são retiradas, em alguns pontos, do artigo de minha autoria, intitulado "Ficções impuras" (ver SOUZA, 2014).
} 
a afirmativa por ambos endossarem raciocínio semelhante quanto à associação simultânea entre textos e imagens, à sequência não cronológica dos acontecimentos, procedimentos definidos por Warburg como iconologia dos intervalos. Seu método heurístico pressupõe a articulação entre o que se situa entre, nos intervalos, desobedecendo a continuidade temporal e endossando princípios anacrônicos. A biblioteca por ele organizada, tendo por título Mnemosyne, responde pelo procedimento de montagem, por agrupar pranchas de natureza díspar, nos âmbitos temático e temporal, com o intuito de apontar simetrias resultantes da exposição de imagens heterogêneas. Ao lado de reproduções de fotos de obras da arte, por exemplo, eram dispostos, em telas de tecido preto, selos postais, baixos-relevos antigos, recortes de jornais, moedas com efígies, gravuras, organização aleatória e fruto de uma montagem que não obedecia à ordem linear de leitura, por sustentar um espaço híbrido de significação.

Da obra de Warburg, o escritor brasileiro não tinha conhecimento quando escreveu Viagem ao México, em 1995, embora convivesse com a obra de Walter Benjamin, herdeiro declarado das teorias antihistoricistas do teórico alemão. Ressalte-se aí o desdobramento do conceito de tradução como sobrevida conferida ao original, o que implica a importância da visita ao passado como desrecalque, como releitura e aproveitamento de conceitos esquecidos pelo cânone oficial. Não é sem razão que o interesse do escritor brasileiro por Warburg, historiador das artes, justifique-se igualmente pela trajetória ficcional realizada no seu livro sobre Artaud, em que se ficcionaliza o encontro do ator europeu com a magia dos rituais indígenas do México. O descontentamento com o ambiente artístico e intelectual europeu na década de 1930 motiva o encontro do artista com a "terra do sol", as drogas e o conhecimento de outras realidades até então desconhecidas do continente americano. Pela mediação de um autor francês em viagem à América Hispânica, Silviano ficcionaliza o entre-lugar do escritor latino-americano, à medida que não só escreve o romance/ensaio, como também se insere na narrativa como duplo de Artaud. Ou vice-versa.

A diferença de Warburg frente aos seus contemporâneos reside ainda na construção de uma "ficção teórica", quando procede à desestabilização da arte ocidental e elabora um método e um estilo novo, ao "escolher objetos inesperados, de que é exemplo a "dança da chuva', ritual cultivado pelos índios do sudoeste norte-americano" 
(SANTIAGO, 2013, p. 181). Nesse sentido, o escritor brasileiro pontua o diálogo com o entre-lugar do discurso latino-americano, por estar o historiador/antropólogo atuando nas pesquisas de modo análogo ao intelectual latino-americano: desloca a arte hegemônica representada pelo Ocidente clássico para o Novo Mundo, por meio da ideia de sobrevivência das formas. A posição do escritor frente à obra de Warburg reside na coincidência em relação ao processo intercultural pautado pelo descentramento e pelo reconhecimento da alteridade. Embora a viagem tenha sido realizada com diferenças - Silviano escolhe como personagem o artista francês na sua ida ao México; Warburg desloca-se literalmente até a América - o diálogo de culturas responde pela defesa da sobrevivência das formas esquecidas e recalcadas pelas culturas das quais fazem parte. Silviano acrescenta a esse diálogo a encenação, pelo romance, da experiência vivida por um europeu em terras do considerado Novo Mundo, com o objetivo de apontar os esquecimentos e desastres provocados pela ação colonizadora.

Mas o que também ressalta neste cruzamento de culturas efetuado pelo autor brasileiro no artigo citado é a inserção da obra de Borges na interpretação de Warburg, ao explicar, sob o olhar enviesado, os passos do historiador na criação de uma "ficção teórica". Por instalar a alteridade no cerne da identidade, modifica, como ficção teórica, a ideia de representação, entendida não como forma de pensar, mas de inventar (MICHAUD, 2013, p. 10) "escritas teórico-críticas lançadas, segundo Marília Cardoso, por pensadores rebeldes do século XIX, das quais se destacam Nietzsche e Freud" (CARDOSO, 2014, p. 134). À feição da poética de Borges, escritor-crítico, situada no limiar entre ficção e ensaio, a experiência do historiador instaura o "saber-montagem", igualmente oscilando entre ciência e invenção. Com atenção obsessiva aos detalhes, aos fragmentos e à produção de uma escrita híbrida e por isso poética, Warburg inaugura distinta diç̧ão, revolucionária no campo da história e da antropologia. Na produção de outro triângulo interpretativo, seria possível conceber Warburg como precursor de Borges e de Silviano, pela confluência entre poéticas. Cito o artigo de Silviano:

$\mathrm{O}$ estudioso da arte da Renascença ensaia de maneira furtiva e subterrânea os primeiros passos em direção à ficção teórica, passos precursores dos dados por Jorge Luis Borges ao escrever o conto "Pierre Menard, autor do Quixote”. (SANTIAGO, 2013, p. 181). 
A reflexão do historiador referente à sobrevivência das formas reveste-se de importância para a ampliação das associações entre os autores postos em relação. Por reforçar o aspecto paradoxal das temporalidades, tem como proposta atualização permanente de temas e conceitos, com vistas a afirmar não serem fatos anteriores a origem de outros que lhes sucedem. Descortina-se, com efeito, a releitura que, obrigatoriamente, deverá ser feita pelas culturas periféricas quanto à hegemonia cultural estrangeira, pela rasura nas origens e na filiação canônica da literatura. A saída para tais embates estaria no meio, no entre-lugar, na aposta de que se sobrevive no presente por meio da substituição das noções de filiação e paternidade pela de aliança. A filiação, em resumo, responderia pela imitação e a identificação, ao passo que a aliança prescreveria a diferença e a alteridade. Didi-Huberman procede à interpretação da sobrevivência warburgiana com a intenção de associar as relações históricas com a cultura e os conceitos aprimorados por diversos pensadores. Contribui, de forma elucidativa, para a reformulação dos conceitos de anacronismo e periodização, presentes em Borges:

A sobrevivência segundo Warburg não nos oferece nenhuma possibilidade de significar a história: impõe uma desorientação terrível para qualquer veleidade de periodização. É uma ideia transversal a qualquer recorte cronológico. Descreve um outro tempo. Assim desorienta, abre, torna mais complexa a história. Numa palavra, ela a anacroniza. Impõe o paradoxo de que as coisas mais antigas às vezes vêm depois das coisas menos antigas. (DIDI-HUBERMAN, 2013, p. 69).

O instinto de sobrevivência estaria presente na poética de Silviano quando emprega na ficção o recurso da mediação e a dramatização do conceito de entre-lugar: Em liberdade (1981), Viagem ao México (1995), Machado (2016), elaboram o procedimento artístico de deslocamento autoral pela incorporação diferenciada do outro, sem a intenção de imitá-lo, mas de suplementá-lo. O olhar frente à tradição se delineia pela introdução do sujeito-escritor sob o olhar da experiência alheia, do afastamento de si em primeira pessoa a fim de se expressar enquanto estranho a si mesmo. Sobrevive com a voz do outro, metaforiza-se na imagem do escritor biografado que se condensa ficcionalmente na autobiografia. A mediação o situa no entre-lugar da tradição literária, 
sem a prisão ao estereótipo da influência, mas se munindo do aparato do distanciamento enunciativo que lhe impulsiona a narrar. Elege seus precursores na qualidade de contemporâneo, apontando coincidências temporais entre obra e vida, restaurando temporalidades esquecidas e diminuindo a distância entre eles. Inaugura uma literatura que se nutre da alteridade e de uma possível comunidade de escritores que dialogam ao longo dos tempos. Assim também endossa Ricardo Piglia, autor de Silviano Santiago:

A verdade tem a estrutura de uma ficção onde um outro fala. Criar na linguagem um lugar para que o outro possa falar. A literatura seria o lugar no qual sempre é o outro que vem dizer. "Eu sou o outro", como dizia Rimbaud. Sempre existe um outro aí. É preciso saber ouvir o outro, para que o que se conta não seja apenas mera informação e tenha a forma da experiência. (PIGLIA, 2001, p. 3, tradução de Rômulo Monte Alto). ${ }^{5}$

Intérpretes de uma modernidade tardia e da experiência alheia como motor criativo, Piglia e Silviano se impõem na defesa dos lugares intermediários e não excludentes de se produzir ficção. O olhar oblíquo do escritor argentino frente à cultura europeia, o olhar estrábico, como poderíamos entender o desvio de visão expressa em outras ocasiões, reúne dois pensadores da América Latina que se distinguiram como escritorescríticos. Trata-se da presença de leitores representantes de uma complexa relação transcultural, por se notabilizarem na condição de inventores de alianças literárias, filosóficas e políticas com os mais distintos pensadores. Ao lado de diferenças de perspectivas autorais e de poéticas, consegue-se vislumbrar a inventiva posição de ambos na apropriação das lições de Borges como precursor de uma aventura em direção à alteridade e ao artifício, à possibilidade de enxertar, brevemente, talvez, a memória de um escritor latino-americano na cabeça de um europeu.

\footnotetext{
5 "La verdad tiene la estructura de una ficción donde otro habla. Hacer en el lenguaje un lugar para que el otro pueda hablar. La literatura sería el lugar en el que siempre es otro el que viene a decir. 'Yo soy otro', como decía Rimbaud. Siempre hay otro ahí. El otro es el que hay que saber oír para que eso que se cuenta no sea una mera información y tenga la forma de la experiencia."
} 


\section{Referências}

ANDRADE, O. Manifesto antropófago. In: . Obras completas: Do pau-brasil à antropofagia e às utopias. Rio de Janeiro: Civilização Brasileira, MEC, 1970.

BORGES, J. L. Carrizo, 1982. In: BORGES, J. L.; FERRER, A. F. (ed.). A/Z: La Biblioteca de Babel. Madrid: Ediciones Siruela, 1988. p. 270.

BORGES, J. L. Pierre Menard, autor do Quixote. In: . Obras Completas I. 1923-1949. São Paulo: Globo, 1999.

BORGES, J. L. Pierre Menard, autor do Quixote. In: . Obras Completas II. 1952-1972. São Paulo: Globo, 1999.

CARDOSO, M. R. A noção de sobrevivência e o refinamento das tarefas críticas. In: SOUZA, E. M.; LYSARDO-DIAS, D.; BRAGANÇA, G. M. Sobrevivência e devir da leitura. Belo Horizonte: Autêntica, 2014. p. 134.

DELEUZE, G.; GUATTARI, F. Mil platôs: Capitalismo e esquizofrenia. Tradução de Aurélio Guerra Neto e Célia Pinto Costa. Rio de Janeiro: Editora 34, 2004. v. 1.

DIDI-HUBERMAN, G. A imagem sobrevivente: história da arte e tempo dos fantasmas segundo Aby Warburg. Rio de Janeiro: Contraponto, 2013. LOPES, D. Do entre-lugar ao transcultural. In: . No coração do mundo: paisagens transculturais. Rio de Janeiro: Rocco, 2012. p. 21-46. MICHAUD, P.-A. Aby Warburg e a imagem em movimento. Tradução de Vera Ribeiro. Rio de Janeiro: Contraponto. 2013.

PIGLIA, R. Borges: el arte de narrar. Tradução de Ricardo Piglia. Cuadernos de Recienvenido, São Paulo, n. 12, p. 5-19, 1999.

PIGLIA, R. Una propuesta para el nuevo milenio. Margens/Márgenes. Cuadernos de Cultura, Belo Horizonte, n. 2, p. 3, out. 2001.

SANTIAGO, S. A literatura brasileira da perspectiva pós-colonial - um depoimento. Conferência proferida no POSLIT/UFMG, como aula inaugural. Belo Horizonte, mar. 2015.

SANTIAGO, S. Borges. In: SCHWARTZ, J. (coord.). Borges no Brasil. São Paulo: UNESP: Imprensa Oficial: Fapesp, 2001. p. 433-434. 
SANTIAGO, S. Renascença: movimento gestual. In: . Aos sábados, pela manhã. Rio de Janeiro: Rocco, 2013.p. 181.

SCHWARZ, R. Nacional por subtração. In: . Que horas são? São Paulo: Companhia das Letras, 1987. p. 29-48.

SOUZA, E. M. A memória de Borges. Aletria, Belo Horizonte, v. 20, n. 2, p. 27-35, 2010. DOI: https://doi.org/10.17851/2317-2096.20.2.27-35 SOUZA, E. M. Ficções impuras. In: BRAGANÇA, G., M.; LYSARDODIAS, D.; SOUZA, E. M. (org.). Sobrevivência e devir da leitura. Belo Horizonte: Autêntica, 2014. p. 111-118.

Recebido em: $1^{\circ}$ de outubro de 2019.

Aprovado em: 7 de fevereiro de 2020. 